survival with that of the age- and sex-matched general population. The cutoff of 50 years was justified for statistical and clinical rationales, which aligns with the need to address an important topic of debate, outcomes in patient $>50$ years old undergoing the Ross procedure. As expected, patients $<50$ years had more previous interventions, unicuspid valves, and aortic regurgitation whereas those $>50$ years had more comorbidities, ie, hypertension, diabetes, dyslipidemia, and lung and coronary artery disease.

We agree with the authors that consideration of the Ross procedure in adults $>60$ years of age should be dictated by lifestyle and hemodynamic reasons in conjunction with a thorough preoperative evaluation and limited to physically fit patients with no comorbidities and small aortic annuli who were at risk of patient-prothesis mismatch.

This study showed comparable perioperative complication and survival rates between groups. Similarly, the cumulative incidence of more than moderate aortic regurgitation (as a surrogate of autograft valve function) and the cumulative incidence of reintervention were not different between groups. These data support the notion of safely expanding the utility of the Ross procedure in carefully selected patients at centers of expertise.

The overall results of this study are promising, but the main limitation is the length of follow-up, with a median of only 2.4 years with only 6-year reintervention and survival data available. Unfortunately, the lack of at least 10-year rates of autograft failure and valve-related mortality precludes the widespread use of the Ross procedure in older patients. Furthermore, $74 \%$ of procedures were performed by a single surgeon, rendering the universal reproducibility of similar results questionable.

In summary, the study of Chauvette and colleagues should stimulate the emergence of further studies to potentially confirm equivalent long-term outcomes between younger and older patients undergoing the Ross procedure. Because of the lack of a sufficient number of surgeons performing this operation due to the preconceived notion of its difficulty and limited reproducibility, along with equipoise among clinicians, a formal randomized trial is unlikely. For these reasons, surgeons should take notice of this important novel indication to the Ross procedure and consider it during the patient-surgeon decision making process.

\section{References}

1. Mazine A, El-Hamamsy I. Procedures and outcomes of surgical aortic valve replacement in adults. Cardiol Clin. 2020;38:89-102.

2. Bansal N, Kumar SR, Baker CJ, Lemus R, Wells WJ, Starnes VA. Age-related outcomes of the ross procedure over 20 years. Ann Thorac Surg. 2015;99:2077-83.

3. Bouhout I, Noly PE, Ghoneim A, Stevens LM, Cartier R, Poirier N, et al. Is the Ross procedure a riskier operation? Perioperative outcome comparison with mechanical aortic valve replacement in a propensity-matched cohort. Interact Cardiovasc Thorac Surg. 2017;24:41-7.

4. Chauvette V, Bouhout I, Tarabzoni M, Wong D, Bozinovski J, Chi MWA, et al. The Ross procedure in patients older than 50: a sensible proposition? J Thorac Cardiovasc Surg. 2022;164:835-44.e5.

\title{
Commentary: How old is too old for the Ross procedure?
}

\section{Tirone E. David, MD}

In this issue of the Journal, Chauvette and colleagues ${ }^{1}$ have a study supporting the performance of the Ross procedure in patients older than 50 of age with expected lifespan greater

From the Division of Cardiovascular Surgery of the Peter Munk Cardiac Centre at Toronto General Hospital and University of Toronto, Toronto, Ontario, Canada.

Disclosures: The author reported no conflicts of interest.

The Journal policy requires editors and reviewers to disclose conflicts of interest and to decline handling or reviewing manuscripts for which they may have a conflict of interest. The editors and reviewers of this article have no conflicts of interest.

Received for publication Oct 6, 2020; revisions received Oct 6, 2020; accepted for publication Oct 8, 2020; available ahead of print Oct 17, 2020.

Address for reprints: Tirone E. David, MD, 200 Elizabeth St, 4N453, Toronto, Ontario M5G 2C4, Canada (E-mail: tirone.david@uhn.ca).

J Thorac Cardiovasc Surg 2022;164:848-9

$0022-5223 / \$ 36.00$

Copyright (c) 2020 by The American Association for Thoracic Surgery

https://doi.org/10.1016/j.jtcvs.2020.10.033

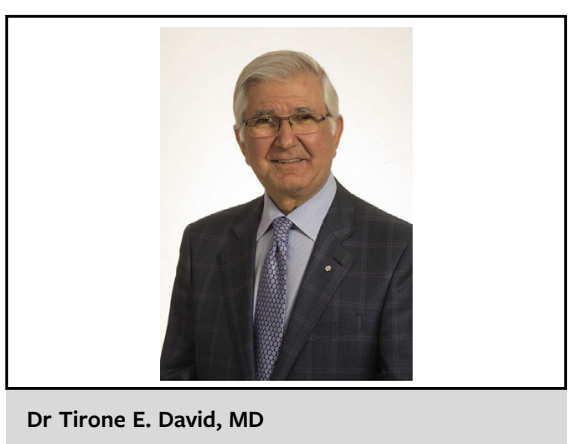

CENTRAL MESSAGE

If a mechanical valve is to be avoided, the Ross procedure may be the best AVR for patients whose lifespan is greater than 15 years. 
than 15 years. The authors certainly believe in their proposal because they described a consecutive series of 497 patients whose mean age was 47 years, and $232(44.6 \%)$ were older than 50 years of age. ${ }^{1}$ In my practice, the mean age was 34 years and only $11 \%$ of patients were older than 50 years of age. ${ }^{2}$ Age by 1-year increment was associated with the development of aortic insufficiency over time by multivariable analysis in my first 212 patients operated on from 1990 through 2004 and prospectively followed for a median of 18 years. ${ }^{2}$ I hypothesized that aging adversely affected adaptation of the pulmonary valve to the systemic circulation. ${ }^{2}$ I have had a similar experience with reimplantation of the aortic valve whereby the aortic valve is placed inside a rigid, noncomplaint structure such as a Dacron graft, and advancing age also adversely affected adaptation and older patients were more likely to develop aortic insufficiency over the years. ${ }^{3}$ The same finding was observed after mitral valve repair for degenerative diseases. ${ }^{4}$

For these reasons, I believed that the Ross procedure was more durable in younger than in older patients, but I don't know at what age this operation should not be done. Having stated all that, aortic valve surgery has changed dramatically during my career. The use of bioprosthetic valves for aortic valve replacement (AVR) has increased during the past 2 decades in patients of all ages, and this trend preceded the development of transcatheter AVR. ${ }^{5,6}$ I believe this move was premature, particularly in individuals younger than 50 years of age or older with expected lifespan $>15$ years. These patients should have a mechanical valve because most bioprosthetic valves will fail and they will require reintervention and probably anticoagulation for life, the oral anticoagulation that was avoided when the first AVR was done. This current trend favoring bioprosthetic valves for AVR will continue in the foreseeable future because of the availability of transcatheter AVR to treat failed bioprosthetic aortic valves. Actually, it is possible that transcatheter AVR will become the first line of therapy for aortic valve disease even in patients younger than 50 years of age or older with expected lifespan $>15$ years. Reoperations in patients with failed transcatheter AVRs are often complex and associated with high mortality and morbidity. ${ }^{7}$ Given the complexity of these reoperations, mechanical valves probably will be used to avoid further reinterventions in young patients. If a mechanical valve had been implanted at the initial AVR, most of these problems could have been avoided.

Aortic valve surgery is likely to become more complicated in the future, and the Ross procedure is not more difficult than reoperations for failed transcatheter AVR. Thus, Chauvette and colleagues may be correct in proposing the Ross procedure for patients whose lifespan is $>15$ years because it will probably provide a far better event-free survival than transcatheter AVR.

\section{References}

1. Chauvette V, Bouhout I, Tarabzoni M, Wong D, Bozinovski J, Chu MW, et al. The Ross procedure in patients older than 50: a sensible proposition? J Thorac Cardiovasc Surg. 2022;164:835-44.e5.

2. David TE, Ouzounian M, David CM, Lafreniere-Roula M, Manlhiot C. Late results of the Ross procedure. J Thorac Cardiovasc Surg. 2019;157:201-8.

3. David TE, David CM, Ouzounia M, Feindel CM, Lafrenier-Roula M. A progress report on reimplantation of the aortic valve. J Thorac Cardiovasc Surg. September 4, 2020 [Epub ahead of print].

4. David TE, David CM, Tsang W, Lafreniere-Roula M, Manlhiot C. Long-term results of mitral valve repair for regurgitation due to leaflet prolapse. J Am Coll Cardiol. 2019;74:1044-53.

5. Brown JM, O’Brien SM, Wu C, Sikora JA, Griffith BP, Gammie JS. Isolated aortic valve replacement in North America comprising 108,687 patients in 10 years: changes in risks, valve types, and outcomes in the Society of Thoracic Surgeons National Database. J Thorac Cardiovasc Surg. 2009;137:82-90.

6. Tam DY, Rocha RV, Wijeysundera HC, Austin PC, Dvir D, Fremes SE. Surgica valve selection in the era of transcatheter aortic valve replacement in the Society of Thoracic Surgeons Database. J Thorac Cardiovasc Surg. 2020;159: 416-27.e8.

7. Fukuhara S, Brescia AA, Shiomi S, Rosati CM, Yang B, Kim KM, et al Surgical explantation of transcatheter aortic bioprostheses: results and clinical implications. J Thorac Cardiovasc Surg. January 12, 2020 [Epub ahead of print]. 